\title{
The Art and Science of Nursing
}

\author{
OLIVEIRA, Margaret de [1] \\ DENDASCK, Carla Viana [2]
}

OLIVEIRA, Euzébio de [3]

OLIVEIRA, Margaret de; et.al. The Art and Science of Nursing. Multidisciplinary Scientific Journal. Special Edition of Health. Year 02, Issue 11, Vol. 04, pp. 18-23, November of 2017. ISSN: 2448-0959

\begin{abstract}
This article aims to bring to light brief reflections on the importance of nursing work in health development. For this, we used bibliographical research with a qualitative approach, proposing to induce reflection and, in a way, to raise awareness of this theme.
\end{abstract}

Key words: Nursing, Health Care, Nursing practice.

\section{INTRODUCTION}

The art of nursing can be described as the caring, compassion, understanding, communicating, and loving in caring for patients. The science of nursing is the pathophysiology, disease process, and techniques learned during the nursing education and applied during patient care. The nurse applies the art and science of nursing when he or she is able to use the scientific knowledge learned from school combined with building a bond with the patient. According to Idczack (2007), the instructors give the nursing student the tools to practice, but it is up to the student to develop and apply what he or she has learned in the class room when interacting with the patients.

The art and science of nursing influences each nurse in such a way that the nurse is no longer seen as a caregiver or a mother figure. The nurse nowadays applies scientific, evidence-based knowledge, critical thinking, and autonomy. The nurse is no longer seen simply as subordinated to the doctor, only taking orders without questioning (Jasmine, 2009). The nurse is now seen as part of a collaborative, healthcare professional group that questions the physician's orders and advocates for the patient when necessary. The root of nursing was known to care for the sick, bringing him or her back to health, and the science of 
nursing was more related to the aspect of cleanliness and nourishment (Castledine, 2010). This has changed in the respect that nursing is now becoming more medicine and evidence based practice, but the nurse still needs to find time for the art aspect of nursing. The art of nursing is unique to each nurse, and the nurse needs to find a balance between time constraints and efficient patient care by using scientific knowledge to provide physical, psychological, and humanistic care.

The art and science of nursing has an influence in my personal nursing practice every day. As a new nurse, I apply the scientific part of nursing on a daily basis as I learn the art of nursing, by interacting with each of my patients. Each patient and situation is unique and requires mental and physical skills that I come up with, that I sometimes don't know I possess. That's what I believe is the art of nursing. I came out of nursing school with the mentality that critical thinking is the key for a successful career and efficient patient care, and I do see the importance of these qualities. The nursing school focused a huge amount of time on pathophysiology and the nursing process. The scientific part of nursing was critical to succeed during nursing school, and it is critical for my day to day patient care. Having knowledge and understanding about the disease process allows me to provide effective and safe patient care. My way of applying the art and science of nursing is by using my time effectively and providing safe patient care. In a way, you have to be creative enough to come up with answers and solutions for problems. I believe the nursing art and science are applied when the nurse has the capability of controlling the situation effectively and uses critical thinking, imagination, and scientific knowledge to provide patient care.

The major influences on the changing health care environment started in Florence Nightingale's era. Nightingale realized that proper environment, sanitation, and care were essential for patient recovery (Selanders, 2010). She used art as evidence based practice knowledge to start the changes in nursing practice. Other important figures include Hildegard Peplau (1952) who identified the importance of patient and nursing relationship and trust during patient care, which is one of the key up to the present day to bring the patient back to health. The trust built between the nurse and the patient allows for better communication and can lead to treatment compliance and faster recovery. Another of the many important figures was Sister Callissa Roy (1980) who describes disease as being a disruption of the human biological, psychological, or social components of life, and the nurse's duty is to bring the patient back to health by balancing all these elements. These and many other important figures followed Nightingale's footsteps by advocating and bringing evidence based practice changes into healthcare practice. Thanks to these brave figures, nurses today are empowered to make changes. Professional nurses can initiate changes in the healthcare environment in many different ways. Many changes in healthcare come from evidence based research, which provides statistical data to support the need for change in a certain area or procedure (Miller, Ward \& Young, 2010). The implementation of these policies ultimately ensures better and safer patient care, improving the nursing practice.

As a new nurse, I only have book knowledge of the changes that have been happening in the nursing profession for the last five years. However, based on my observations, these changes have been successful. Nurses are more independent and they use scientific based knowledge to make changes to their work environment. Nurses are able to provide patient care in an effective manner by applying research based evidence to their practice, therefore guaranteeing safe and improved patient care. The use of technology also is changing nursing care. The nurse nowadays must have computer knowledge to be able to work efficiently. The nurse also must have vast knowledge about science to apply nursing care combined with the art of nursing, which is the caring and human touch the nurse provides. According to Castledine (2010), the science and technological part of nursing is becoming dominant and the nurses are 
risking losing the caring and humanistic part of nursing. Therefore, it is our obligation as nurses to apply science and humanistic care combined with the advances in technology to improve patient outcomes.

Strategies I have employed to apply the knowledge of art and science of nursing into my practice are simple yet true to the nursing profession. I take care of each patient with the sole intention of bringing him or her back to health or at least to a comfortable level. The key to applying the art of nursing care according to Idczack (2007) is for the nurse to be aware of his or her own biases, morality, principles, morals, and overall awareness which will allow the nurse to know his or her own limitations, and will allow for realistic and effective patient care. As a new graduated nurse I'm still learning on a daily basis about my overall perception of patient care. However, I use every opportunity to apply what I have read or learned from school to improve my patient's health. The lack of confidence and exposure to different clinical situations can be overwhelming sometimes, but I feel that sometimes your natural instincts kick in and you know instantly what to do to save or protect your patient. This could be one of the hidden arts in nursing: something that you are simply born with and have no scientific explanation for. I try using all my senses to connect and understand my patients as I provide the care needed. I apply the art and science of nursing by using the skills learned in school combined with my instincts. I show professionalism, compassion, and kindness. I simply show my patients that I care and that is how I make a connection with each of them. The ability to connect with and help my patients gives me a sense of accomplishment and to love my profession even more.

My strategies after finishing my nursing education will be to continue to apply evidence-based practice into my patient care. I also intend to work in a collaborative team as I'm developing my nursing career and implement the theories and critical thinking I have learned. I plan to use proper communication and technological resources while working as part of a team to improve patient care and safety. I will definitely continue to apply and learn more about the art and science of nursing, such as becoming more diligent and perceptive of my patients' needs by using cultural sensitivity and scientific knowledge. This will enrich my nursing practice, bringing improvement to patient care and safety. I intend to continue on with my education to improve my technological and science knowledge while using the art of nursing to care for my patients.

\section{REFERENCE}

Castledine, G. (2010). Creative nursing: Art or science?. British Journal of Nursing (Mark Allen Publishing), 19(14), 937.

Jasmine, T. (2009). Art, science, or both? Keeping the care in nursing. Nursing Clinics of North America, $44(4), 415-421$.

Idczak, S. (2007). I am a nurse: Nursing students learn the art and science of nursing. Nursing Education Perspectives, 28(2), 66.

Miller, L. , Ward, D. , \& Young, H. (2010). Evidence-based practices in nursing. Generations-journal of the American Society on Aging, 34(1), 72-79.

Nightingale F. (1992). Notes on nursing: What it is, and what it is not, Commemorative edn. London: Lippincott Williams and Wilkins. 
Peplau H.E. (1952). Interpersonal relations in nursing. Putnam’s Sons, New York.

Roy C. (1980). The Roy Adaptation Model. In Conceptual Models for Nursing Practice, 2nd edn (Riehl J.P. \& Roy C. ed). Appleton-Century-Crofts, Norwalk, Connecticut, 179-188.

Selanders, L. (2010). The power of environmental adaptation: Florence nightingale's original theory for nursing practice. Journal of Holistic Nursing, 28(1), 81-88.

[1] Registered Nurse e Bachelors in Nursing Science. USA - California

[2] PhD in Clinical Psychoanalysis, Researcher at the Center for Research and Advanced Studies.

[3] Biologist. Doctor of Medicine / Tropical Diseases. Professor and Researcher at the Federal University of Pará - UFPA. Researcher at the Laboratory of Human and Environmental Toxicology and in the Laboratory of Oxidative Stress of the Nucleus of Tropical Medicine of UFPA (NMT-UFPA).

\section{PUBLIQUE SEU ARTIGO CIENTÍFICO EM:}

https://www.nucleodoconhecimento.com.br/enviar-artigo-cientifico-para-submissao 